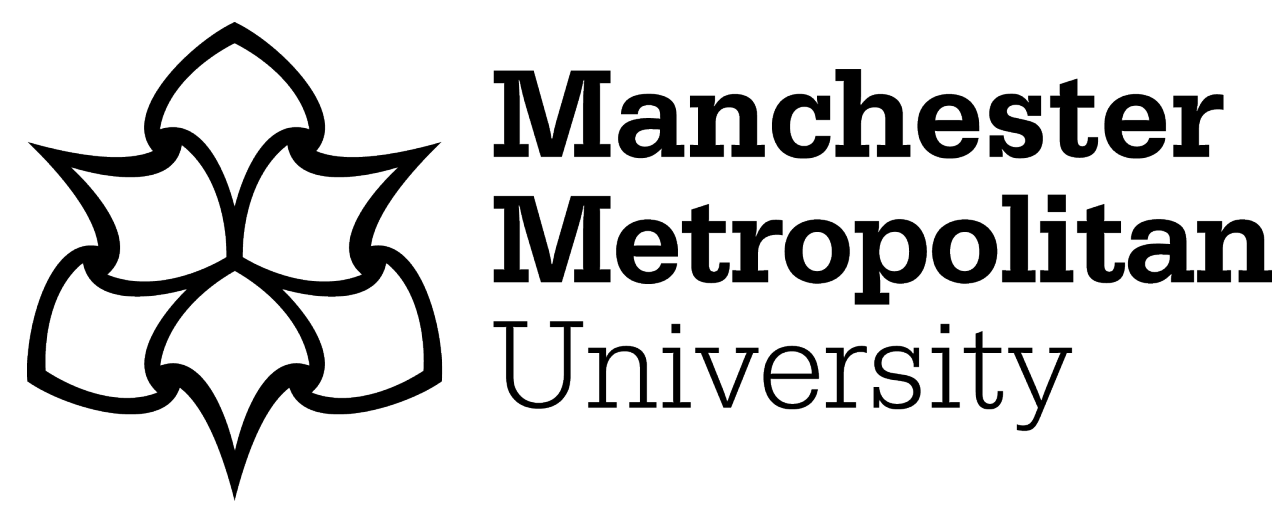

Inoue, Yuhei ORCID logoORCID: https://orcid.org/0000-0002-1983-6217 (2015) Event-Related Attributes Affecting Donation Intention of Special Event Attendees: A Case Study Event-Related Attributes Affecting Donation. Nonprofit Management and Leadership, 26 (3). pp. 349-366. ISSN 1048-6682

Downloaded from: https://e-space.mmu.ac.uk/624281/

Version: Accepted Version

Publisher: Wiley

DOI: https://doi.org/10.1002/nml.21192

Please cite the published version 
Event-Related Attributes Affecting Donation Intention of Special Event Attendees:

A Case Study

Yuhei Inoue

\begin{abstract}
Author Identification
Yuhei Inoue is an assistant professor of sport management in the School of Kinesiology at the University of Minnesota in Minneapolis, MN.
\end{abstract}

Please cite this article as: Inoue, Y. (2016). Event-related attributes affecting donation intention of special event attendees: A case study. Nonprofit Management \& Leadership, 26(3), 349-366. http://dx.doi.org/10.1002/nml.21192 


\section{Event-Related Attributes Affecting Donation Intention of Special Event Attendees:}

\section{A Case Study}

Promoting donations through special events has significant financial implications for charitable organizations. However, little is known about how such events can be organized to increase individuals' donation intention beyond their event attendance. In this case study, a postevent survey was conducted with attendees of a professional golf tournament operating as a special event to identify event-related attributes that affected their intention to donate to the cause supported by the event. The results indicate that attendees' donation intention was positively associated with their event satisfaction, perceived contributions of the event to the cause, and sense of camaraderie at the event. Furthermore, the effects of event satisfaction and camaraderie were stronger for attendees whose primary motivation for attending the event was unrelated to cause support. These results support hypotheses drawn from social exchange theory and provide implications for charitable organizations engaging in special events.

Keywords: fundraising, charity, marketing, reciprocity, survey research 
Special events are a popular form of fundraising that integrates the support of a cause with a leisure activity to attract a broad range of donors, including those who may not have a strong interest in the cause (Wharf Higgins and Lauzon 2003). Leisure activities frequently used for this purpose include music concerts, physical activity and sport participation, and sport spectatorship (Einolf, Philbrick, and Slay 2013; Filo, Funk, and O’Brien 2009; Inoue and Havard 2014; Parris and Welty Peachey 2012; Wharf Higgins and Lauzon 2003). For example, in 2005, four different concerts organized after Hurricane Katrina to support the disaster relief efforts of the American Red Cross and other charitable organizations raised a total of \$110 million (Einolf, Philbrick, and Slay 2013). The Coaches vs. Cancer Classic, a competitive men's intercollegiate basketball tournament assisting the American Cancer Society in its efforts for cancer prevention and care, generated over $\$ 85$ million for the organization, together with other associated events (National Association of Basketball Coaches 2012).

Despite these successful examples, direct revenues from special events typically account for a small proportion of total revenue for a charitable organization (Wharf Higgins and Lauzon 2003). Yet special events have significant financial implications for a charitable organization because, if successfully organized, they effectively facilitate increased support from current donors while fostering a new donor base (Webber 2004). In essence, the operations of a special event are justified by the event's ability to encourage future donations among event attendees beyond their participation in the event (Webber 2004). One issue, however, is that many charitable organizations "fail to develop the people who attend events into more productive donors and do not take the opportunity at the event to engage them further" (Webber 2004, 132). A recent study highlighted this issue by demonstrating that merely attending a special event does not necessarily lead individuals to strengthen their relationship with the charitable organization 
(Woolf, Heere, and Walker 2013). To leverage the ability of special events to promote individual giving, charitable organizations must understand factors that would determine attendees' future donations.

To date, extant studies on special events have focused on understanding motivations for event participation (Filo, Funk, and O’Brien 2009; Hendriks and Peelen 2013; Wharf Higgins and Lauzon 2003), with some additional research on business benefits for event sponsors (Cornwell and Coote 2005), the social impact of an event on the host community (Inoue and Havard 2014), and factors affecting attendees' intention to attend a future event (Hendriks and Peelen 2013; Taylor and Shanka 2008). Although these studies have addressed important issues, evidence is lacking as to how such events can be organized to increase future donation intention among attendees. In addition, a substantial body of research has identified factors that can affect the decision to donate money to a charitable organization (Bekkers and Wiepking 2011) as well as enhance donors' loyalty to the organization (Sargeant 2001; Sargeant and Woodliffe 2007). Although evidence from this body of research is highly relevant to the context of special events, no attempt has been made to apply this evidence base to explain what influences attendees' donation intention.

The purpose of this study was to advance the field's understanding of a special event by identifying event-related attributes that might affect the donation intention of event attendees. To this end, I adopted social exchange theory (Cropanzano and Mitchell 2005) as a theoretical framework because of its demonstrated utility in explaining charitable giving (Leslie, Snyder, and Glomb 2013).

\section{Social Exchange Theory}


Social exchange theory is a paradigm for understanding interdependent transactions where actions of one entity depend on actions of another (Cropanzano and Mitchell 2005). Such mutually contingent transactions can be observed in various forms of exchange varying in complexity, with the simplest form being a two-party relationship in which one party "gives to and receives from" the other (Bagozzi 1975, 32). In this form of exchange, two parties attempt to maintain equality between the parties by providing something of value in return for something of value (Bagozzi 1975; Levi-Strauss 1969). In the workplace, for example, employees are likely to give benefits (such as greater work effort) to their employing organization to the extent they receive benefits (such as compensation) from the organization (Cropanzano and Mitchell 2005). From this perspective, charitable giving can be characterized as a form of exchange: donors give money to a charitable organization, and, in return, they gain some value or benefits from the organization (Bekkers and Wiepking 2011; Sargeant and Hudson 2008).

The benefits charitable organizations provide to a donor relate to extrinsic and intrinsic motivations (Ariely, Bracha, and Meier 2009). Extrinsic motivation entails any material rewards associated with giving, such as gifts and tax breaks, whereas intrinsic motivation involves psychological rewards or benefits, including positive self-image and joy of giving (Ariely, Bracha, and Meier 2009). Research has demonstrated that the provision of value, especially psychological benefits, is positively associated with charitable giving (Bekkers and Wiepking 2011). The importance of increasing the perception of benefits from charitable giving was further highlighted by Sargeant and Hudson (2008) who suggested that "donors receiving greater personal value from their gifts (in whatever form) will be significantly more likely to be loyal" (91). Specifically, in the context of door-to-door fundraising, the researchers found that, when compared to lapsed supporters, active supporters of a charity who continued to donate after being 
recruited by a fundraiser tended to find greater value, such as feelings of appreciation and selfimportance, in their donations (Sargeant and Hudson 2008).

Similar to charitable giving in general, special events build on reciprocal relationships where event participants receive benefits (for example, participation in leisure activities) in exchange for providing a participation fee to the charitable organization operating the event (Webber 2004; Wharf Higgins and Hodgings 2008; Wharf Higgins and Lauzon 2003; Woolf, Heere, and Walker 2013). According to social exchange theory (Cropanzano and Mitchell 2005) and research on charitable giving (Bekkers and Wiepking 2011), attendees would likely give more to an organization when they perceive greater benefits from their event participation. Therefore, if a charitable organization seeks to elicit financial support beyond participation fees from event attendees, the organization must increase their perceived personal benefits from the special event.

The aforementioned discussion leads to a key research question: what event-related attributes will affect the perception of benefits from attending a special event and thus increase attendees' intention to donate to the cause supported by the event? To address this question, I developed a research model as presented in Figure 1. Building on social exchange theory and the literature on charitable giving and special events, I identified the following three event-related attributes that would influence attendees' perceived benefits of a special event and thus predict their donation intention: event satisfaction, perceived event contribution, and camaraderie. In addition, I expected the effects of two attributes — event satisfaction and camaraderie — on donation intention to be moderated by event attendance motivation. The next section provides a detailed rationale for each hypothesis specified in the model.

[Figure 1 Here] 


\section{Event-Related Attributes Affecting Donation Intention}

\section{Event Satisfaction}

Wharf Higgins and Lauzon's (2003) observation of 12 different special events in Canada found that enjoyment through leisure participation represents a primary reason for event attendance. Given this finding, social exchange theory (Cropanzano and Mitchell 2005) posits that attendees would perceive greater benefits from a special event and hence would be more likely to donate to the cause if the event allowed them to satisfy their needs to enjoy the leisure aspect of the event. In the event literature, the fulfillment of the hedonic needs (that is, enjoyment from leisure) has been assessed by measuring event satisfaction (Yoon, Lee, and Lee 2010). Event satisfaction refers to attendees' evaluative response to their event experience (Yoon, Lee, and Lee 2010). From the perspective of consumers, satisfaction primarily captures an emotional response, described by such terms as "I'm happy" (Giese and Cote 2000). Hence, it is appropriate to measure event satisfaction in assessing the extent to which attendees gain enjoyment from their leisure experience at a special event. To date, no research has demonstrated the direct relationship between event satisfaction and donation intention. Taylor and Shanka (2008) and Hendriks and Peelen (2013), however, found that attendees' satisfaction with a special event had a positive association with their intention to participate in future events. The effect of satisfaction on charitable giving has also been supported by studies of alumni donations to universities (Gaier 2005) and members' donations to professional associations (Wang and Ashcraft 2014). Extending these findings, I tested the following hypothesis:

Hypothesis 1: Attendees' level of event satisfaction will be positively associated with their intention to donate to the cause supported by the special event.

\section{Perceived Event Contribution}


Another major reason that attracts people to a special event is to support a worthy cause (Filo, Funk, and O’Brien 2009; Hendriks and Peelen 2013; Wharf Higgins and Lauzon 2003). Charitable giving can generate positive psychological consequences for donors (Bekkers and Wiepking 2011). Similarly, at special events, some attendees gain psychological rewards, such as a sense of meaningfulness, by perceiving that they significantly contribute to the cause through their event participation (Filo, Funk, and O'Brien 2009; Inoue and Havard 2014). Drawing from social exchange theory (Cropanzano and Mitchell 2005), I expected that individuals would be more likely to perceive that they benefitted from participating in the event (and thus give back to the charitable organization through donations) as their perceived event contribution- - the perception of the event's level of charitable contributions to the cause-increased.

An additional rationale for the relationship between perceived event contribution and donation intention is that the establishment of social norms among attendees might partially mediate this relationship. Research examining the effects of social norms has demonstrated that people likely perform a behavior if they think that others also engage in the behavior and thus the norm to perform that behavior is developed (Croson, Handy, and Shang 2009; Leslie, Snyder, and Glomb 2013). For example, in a recent workplace study, male employees donated more to a workplace charity if they worked in a unit with a higher percentage of female employees, who tend to engage in charitable giving more actively than their male counterparts (Leslie et al., 2013). A study of donors to a public radio station (Croson, Handy, and Shang 2009) found that the amount of donations made by a donor was positively associated with his or her perceptions of descriptive social norms, or "belief of what others are contributing" (p. 468). In a special event, charitable organizations often communicate information on the amount of money raised for their cause from the current and previous events to attendees through websites, press releases, and 
onsite information booths. Therefore, event attendees who are exposed to this information and believe that the event contributed greatly to the cause (as indicated by a high level of perceived event contribution) would be more likely to perceive charitable giving as a social norm and form intention to donate to the cause. Based on the aforementioned logic, the next hypothesis was as follows:

Hypothesis 2: Attendees' perceived event contribution will be positively associated with their intention to donate to the cause supported by the special event.

\section{Camaraderie}

Camaraderie refers to a sense of belonging and solidarity enhanced through the development of warm relationships with other event attendees (Filo, Funk, and O’Brien 2014). Research on charitable giving has demonstrated that some people give money or time to a cause in order to connect with their family and friends and be part of a community (Curtis, Cnaan, and Evans 2014; Prince and File 1994). Similarly, for some attendees, special events serve as a place to socialize and enjoy camaraderie (Filo, Funk, and O'Brien 2009; Hendriks and Peelen 2013; Taylor and Shanka 2008). Furthermore, the camaraderie experienced through event participation increases attendees' attachment to a special event (Filo, Funk, and O’Brien 2009). Social exchange theory (Cropanzano and Mitchell 2005) thus suggests that the extent to which people feel a sense of camaraderie determines their perceived benefit of a special event and subsequently their intention to donate to the cause.

The concept of social capital is also useful in understanding the effect of camaraderie on donation intention. Social capital entails "networks, norms, and social trust that facilitate coordination and cooperation for mutual benefit" (Putnam 1995, 67). The camaraderie generated at events helps attendees increase their social capital (Chalip 2006). According to Putnam 
(1995), the development of social capital creates norms of reciprocity, and these norms, in turn, encourage people to pay attention to the welfare of others. Indicators of social capital, such as formal and informal social networking, social ties, and trust in others, can further influence decisions to engage in charitable giving and volunteering (Brown and Ferris 2007; Forbes and Zampelli 2014; Sokolowski 1996; Wang and Graddy 2008). Based on the identified role of social capital in giving and the tenet of social exchange theory, I expected the camaraderie experienced at a special event to influence attendees' intention to donate to the cause:

Hypothesis 3: The camaraderie experienced by attendees at the special event will be positively associated with their intention to donate to the cause supported by the event.

\section{Interaction Effect of Event Attendance Motivation}

Motivation represents a psychological force that directs actions (Filo, Funk, and O'Brien 2014). Research has identified various motivations explaining why people attend a special event (Filo, Funk, and O'Brien 2014; Hendriks and Peelen 2013; Taylor and Shanka 2008; Wharf Higgins and Lauzon 2003). For example, Hendriks and Peelen (2013) found that the motivation to participate in a cycling event raising funds for cancer research can be categorized into cause (giving to a charitable organization addressing cancer care), humanity (supporting cancer patients and families), empowerment (making cancer a priority), personal (having personal connection to cancer), social (socializing with friends), and well-being (enjoying sport participation). Examining another cycling event, Filo, Funk, and O'Brien (2014) identified eight motivations similar to those identified by Hendriks and Peelen and further classified these motivations into charity-based (giving to a charitable organization) and recreation-based (participating in a leisure activity) motivations. That the motivation for attending a special event can be distinguished by whether it relates closely to cause support or other more recreational 
aspects of the event, such as leisure participation and socialization, was further demonstrated by Wharf Higgins and Lauzon (2003) who examined 12 different special events in Canada.

Of the three event-related attributes hypothesized above, perceived event contribution relates to the motivation of cause support, and, when compared to this attribute, event satisfaction and camaraderie are more closely associated with noncause attendance motivations, such as leisure participation and socialization (Filo, Funk, and O'Brien 2014; Wharf Higgins and Lauzon 2003). Individuals whose primary motivation for event attendance relates to cause support are more likely to support the cause beyond attendance than those attending the event for other reasons (Cornwell and Coote 2005). Therefore, one important goal of charitable organizations is to develop attendees who did not originally have a strong interest in the cause into active donors (Webber 2004; Wharf Higgins and Lauzon 2003). According to social exchange theory (Cropanzano and Mitchell 2005), when individuals attend a special event to fulfill a noncause motivation (enjoyment through leisure participation, socializing with others), the greater level of event satisfaction and camaraderie (which are linked more closely to a noncause motivation as noted) they experience at the event, the more likely they are to perceive that they have benefitted from the event and to form an intention to reward the charitable organization by donating to its cause. Based on this theoretical proposition, I developed the following two hypotheses on the interaction effects of primary attendance motivation on the relationship between each of the two event-related attributes - event satisfaction and camaraderie - and donation intention:

Hypothesis 4: The positive relationship between event satisfaction and donation intention will be stronger if cause support is not attendees' primary motivation for event attendance. 
Hypothesis 5: The positive relationship between camaraderie and donation intention will be stronger if cause support is not attendees' primary motivation for event attendance.

\section{Sociodemographic and Participation Characteristics}

Charitable giving is associated with various sociodemographic characteristics (Leslie, Snyder, and Glomb 2013; Wang and Ashcraft 2014; Wang and Graddy 2008). For example, women were found to donate more than men (Leslie, Snyder, and Glomb 2013), and the likelihood of charitable giving tends to increase with age and income (Wang and Ashcraft 2014). Charitable giving can also be influenced by race (Leslie, Snyder, and Glomb 2013), education (Wang and Ashcraft 2014; Wang and Graddy 2008), and resident status (Wang and Graddy 2008). Therefore, in testing the hypotheses proposed above, I took into account the potential effects of sociodemographic characteristics on donation intention by measuring gender, race, age, education, income, and resident status. In addition, based on the evidence that attendees' support for a charitable organization is associated with the characteristics of their participation in its special event (Cornwell and Coote 2005), I controlled for the effect that attendees' level of event participation might have on donation intention.

\section{Method}

\section{Study Setting and Participants}

The setting of this study was a professional golf tournament (hereafter "the Tournament") held annually in a major city in the southern United States. Since its inception, the Tournament has been organized as a special event to raise funds for a local nonprofit hospital (hereafter "the Hospital") for pediatric cancer and other catastrophic diseases. The weeklong event consists of four tournament rounds and specific events and activities to support the Hospital, such as a fundraising concert and a pro-am golf competition. Through event revenues and extensive 
fundraising efforts, the Tournament has generated over \$25 million for the Hospital since the 1970s.

This study represents part of a large project to understand the event-related attitudes and behaviors of Tournament attendees (Inoue and Havard 2014; Inoue, Havard, and Irwin forthcoming). A postevent web-based survey was conducted with attendees of the 2012 event 1 week after its conclusion in June 2012. The study population was all event attendees (according to the event organizer's estimate, approximately 100,000 people attended the event throughout the week), and the sample consisted of conveniently selected attendees whose email address was collected from one of the following two sources: (a) the event organizer's database that included about 7,000 email addresses of event attendees, and (b) a short survey conducted by the author at the event site $(n=537)$. For the latter source, this short survey was used only to gather contact information, and all study variables were collected through the web-based survey.

Over 4 weeks and with two reminder emails, 696 respondents provided usable responses for all survey items relating to the study variables and constituted the final sample. This resulted in an approximate usable response rate of 9\%. Full information on the demographic and sociodemographic characteristics of the 696 respondents is provided in Table 1. Overall, $73.4 \%$ of the respondents were male; $91.7 \%$ were White; $72.3 \%$ were 45 years or older; $69.3 \%$ had at least a 4-year college degree; $77.6 \%$ had an annual household income of more than $\$ 50,000 ; 63.5 \%$ were from the local county; and $73.9 \%$ indicated that their primary motivation for event attendance was to support the Hospital.

\section{[Table 1 Here]}

Given the low response rate, this study may be subject to nonresponse bias, which is concerned with the extent to which the usable sample represents the original sample (Lindner, 
Murphy, and Briers 2001). To address this concern, I conducted a procedure for handling nonresponse bias, which compares early to late respondents on their known characteristics (Lindner, Murphy, and Briers 2001). Specifically, I rank-ordered the 696 respondents based on their survey completion dates and compared 348 respondents within the first $50 \%$ to 348 respondents within the latter 50\% regarding gender, race, age, education, and income. Analyses using chi-square tests indicated that the two groups significantly differed in age only: the late respondent group, which is expected to be similar to nonrespondents (Lindner, Murphy, and Briers 2001), included a greater proportion of older adults (55 years and above) than the early respondent group. This result seems to suggest that younger attendees were overrepresented in the final sample, and this potential overrepresentation should be taken into account in interpreting the results.

\section{Study Variables}

All study variables were measured through the postevent survey. In this survey, the order of the questions measuring the study variables was randomized to address potential common method bias that could result from the use of a cross-sectional design (Podsakoff et al. 2003).

Donation intention. Consistent with Ferguson, Farrell, and Lawrence (2008), respondents' donation intention was measured with a single item asking to indicate their likelihood of donating to the Hospital after the event. The response categories for this item ranged from 1 (very unlikely) to 7 (very likely). A frequency analysis of this variable revealed that it had a negatively skewed distribution (skewness $=-1.46$; kurtosis $=1.81$ ). Following the suggestion of Tabachnick and Fidell (2006), a reflect and inverse transformation was performed for this variable to improve the data distribution, and the transformed values were used for subsequent analyses. For this transformation, the original values were first reflected by 
subtracting them from a constant (8); in turn, the reflected values were inversed to create the transformed variable (Tabachnick and Fidell 2006).

Independent variables. Three variables were measured to test Hypotheses 1-3. First, two 7-point scale items from Yoon et al. (2010) were used to assess attendees' levels of event satisfaction $(\alpha=.79)$ : "I am satisfied with the Tournament this year." and "I am happy that I attended the Tournament this year." Second, perceived event contribution was measured with two 7-point scale items adapted from Lichtenstein, Drumwright, and Braig (2004: $\alpha=.85)$ : "The Tournament is committed to using its profits to help the Hospital." and "The Hospital benefits from donations generated by the Tournament." Finally, respondents' sense of camaraderie at the Tournament was measured with three 7-point scale items from Filo, Funk and O'Brien (2014): "Attending the Tournament allowed me to develop warm relationships with others." "Attending the Tournament provided me with a sense of belonging." and "I felt closeness towards the other attendees at the Tournament" $(\alpha=.84)$.

As with donation intention, the three independent variables had a negatively skewed distribution: skewness of -4.53 and kurtosis of 37.95 for event satisfaction; skewness of -1.96 and kurtosis of 4.47 for perceived event contribution; and skewness of - .53 and kurtosis of -.22 for camaraderie. Therefore, these variables were transformed with a reflect and inverse function (Tabachnick and Fidell 2006).

Interaction variables. Consistent with Cornwell and Coote (2005), respondents' primary motivation for event attendance was measured using the question "What was the primary reason(s) that you attended the Tournament this year?" Several reasons that reflect different types of motivation were provided as response options, and respondents were allowed to indicate multiple primary reasons that applied to them. For this study, 182 respondents $(26.1 \%)$ who did 
not check the option "to support the Hospital" were identified as individuals attending the event based on a noncause motivation $(1=\operatorname{did}$ not check; $0=$ checked $)$. Multiplying this variable with event satisfaction and camaraderie, two interaction variables were created to test Hypotheses 4 and 5.

Control variables. Given the potential effects of sociodemographic and participation characteristics on donation intention (Cornwell and Coote 2005; Leslie, Snyder, and Glomb 2013; Wang and Ashcraft 2014; Wang and Graddy 2008), the following variables were included as control variables: gender $(1=$ male; $0=$ female $)$, race $(1=$ White; $0=$ other race $)$, age (ranging from 1 [18 to 19 years old] to 7 [65 years old and over]), education (ranging from 1 [less than high school] to 6 [graduate degree]), income (six dummy variables based on the first six household income categories in Table 1; the category $\$ 200,001+$ was specified as the reference group), resident status ( $1=$ local residents; $0=$ visitors), and the level of event participation (the total number of specific events that respondents attended during the Tournament week, such as regular rounds, pro-am competition, and fundraising concert).

\section{Analysis and Results}

Table 2 shows the descriptive statistics and correlations for the independent and dependent variables. In addition, Table 3 presents the results of four hierarchical multiple linear regression models performed to test the study hypotheses. Model 1 of Table 3 represents a baseline model, which includes only noncause motivation and the other control variables. This model explained approximately $10 \%$ of the variance in donation intention $\left(R^{2}=.12\right)$. As shown in Model 2, the inclusion of the three independent variables led to a significant increase in the amount of the variance explained for donation intention from the baseline model, $\Delta R^{2}=.10, p$ $<.001$. Specifically, each of the independent variables - event satisfaction $(B=0.20, t=2.91, p$ 
$=.004)$, perceived event contribution $(B=0.29, t=5.35, p<.001)$, and camaraderie $(B=0.13, t$ $=2.87, p=.004)$ - had a significant, positive association with the dependent variable. These results confirmed Hypotheses 1-3.

\section{[Table 2 Here]}

[Table 3 Here]

Models 3 and 4 tested the interaction effects of noncause motivation with event satisfaction and camaraderie. Only one interaction variable was included in each model to avoid multicollinearity. In addition, these models focused on the effects of the interaction variables because the coefficients of the independent variables constituting the interaction variables represented their conditional effects when noncause motivation had a value of 0 (Brambor, Clark, and Golder 2006). Model 3 assessed the interaction effect between noncause motivation and event satisfaction (Noncause Motivation $\times$ Event Satisfaction). Consistent with Hypothesis 4 , this variable had a significant, positive effect on donation intention $(B=0.25, t=2.01, p=.05$, $\Delta R^{2}=.01$ ), indicating that the positive association between event satisfaction and the dependent variable increased for respondents with a noncause motivation. As shown in the upper graph of Figure 2, while attendees with a cause motivation consistently indicated greater donation intention than those with a noncause motivation, the difference in the intention between the two groups decreased as the level of event satisfaction increased.

In Model 4, the interaction variable between noncause motivation and camaraderie (Noncause Motivation $\times$ Camaraderie) had a significant, positive effect on donation intention, $B$ $=0.28, t=2.90, p=.004, \Delta R^{2}=.01$. The direction of the coefficient for the interaction variable suggested that camaraderie had a stronger association with the dependent variable when respondents' primary motivation for event attendance was not linked to cause support. The lower 
graph of Figure 2 showed that attendees with a noncause motivation indicated the greater intention to donate to the cause at a very high level of camaraderie than those with a cause motivation. This result supported Hypothesis 5.

[Figure 2 Here]

\section{Discussion}

This study's investigation of a professional golf tournament operating as a special event reveals that the three event-related attributes drawn from social exchange theory-event satisfaction, perceived event contribution, and camaraderie-significantly explained attendees' donation intention. These results indicate that the extent to which attendees of a special event intend to support its cause through donations can be influenced by how the event increases the attendees' perceived benefits from the event. Consistent with social exchange theory, the results of the interaction effects of the primary attendance motivation further show that increasing event satisfaction and camaraderie at special events is particularly effective in promoting the donation intention of attendees with a noncause motivation.

\section{Theoretical Implications}

The findings of this study contribute to the literature on special events by addressing the lack of evidence on what influences attendees' donation intention. The three event-related attributes examined in this study accounted for roughly $10 \%$ of the variance in attendees' donation intention beyond their personal characteristics. This result suggests that a charitable organization can promote attendees' support for the cause by increasing their perception of benefits from the special event, extending previous research that viewed cause support as a stable characteristic of attendees (Filo, Funk, and O’Brien 2014; Webber 2004; Wharf Higgins and Lauzon 2003). In addition, the finding supports the existing evidence highlighting the role of 
event satisfaction in special events (Hendriks and Peelen 2013; Taylor and Shanka 2008) and adds to this evidence base by demonstrating that, beyond event satisfaction, perceived event contribution and camaraderie can influence attendees' intention to benefit the cause through donations.

Another contribution of this study relates to the finding indicating that the event attendance motivation moderated the effects of event satisfaction and camaraderie on donation intention. Although the importance of examining motivations in determining how to approach certain segments of event attendees has been discussed previously (Hendriks and Peelen 2013; Webber 2004), an analysis of how a given motivation interacts with specific event-related attributes has been lacking. This study is the first to show that the influence of certain attributes depends on attendees' motivation. The interaction effect for camaraderie is particularly promising because it suggested that attendees with a noncause motivation would more likely donate to the cause than attendees with a cause motivation when the event was perceived to generate a very strong level of camaraderie. Yet given that the interaction variables explained only a small proportion of the variance in donation intention, identifying the interactions between other attendance motivations and event-related attributes is essential to better predict intention.

This research contributes to the charitable giving literature by finding that attributes relating to key drivers of charitable giving, including psychological benefits (Bekkers and Wiepking 2011), satisfaction (Wang and Ashcraft 2014), social norms (Croson, Handy, and Shang 2009; Leslie, Snyder, and Glomb 2013), and social capital (Brown and Ferris 2007; Forbes and Zampelli 2014; Wang and Graddy 2008), can predict the donation intention of special event attendees. Special events have been recognized as an effective setting to solicit donations (Webber 2004; Wharf Higgins and Hodgings 2008). In a survey with participants of a 
special event (Wharf Higgins and Hodgings 2008), nearly $80 \%$ of the respondents indicated that this particular event "was definitely a better way to raise funds for a charity" (56) than other solicitation methods, such as door-to-door solicitations and direct mailings. Despite the presumed advantages of special events, the literature has made little effort to apply the existing knowledge on charitable giving to these events [for example, a comprehensive review of empirical studies on charitable giving by Bekkers and Wiepking (2011) made no specific mention of special events]. The current investigation informs the literature that understanding solicitation through special events serves as an important avenue for future research.

Finally, although past studies on special events (Webber 2004; Wharf Higgins and Lauzon 2003; Woolf, Heere, and Walker 2013) indicated that special events rest on reciprocal exchanges between charitable organizations and attendees, none of the studies have articulated the relevance of social exchange theory to those events. Despite its long history, social exchange theory still suffers from theoretical and empirical ambiguities, and testing the extent to which this theory is applicable to a given setting represents a critical issue (Cropanzano and Mitchell 2005). This study contributes to social exchange theory by explicitly extending its theoretical propositions to the context of special events.

\section{Practical Implications}

The strong support for social exchange theory (Cropanzano and Mitchell 2005) found in this study indicates that a charitable organization should strive to maximize attendees' perceived benefits from its special event to increase the likelihood that they engage in future giving. Given the significant effects of the three event-related attributes identified in this study, the following suggestions can be made for enhancing the perception of benefits from special events. First, the finding that perceived event contribution affected donation intention highlights the importance of 
disseminating messages that promote the event's key role in cause support among attendees through various communication platforms (for example, onsite signage, giveaways, social media) and ancillary activities (for example, education booths, testimonials from recipients of support). Such messages should emphasize the contribution made by each attendee's participation fees to the event's overall cause support in order to increase the "joy of giving" (Bekkers and Wiepking 2011) and thus produce psychological benefits for attendees.

Moreover, based on the results that camaraderie and event satisfaction influenced donation intention, charitable organizations should attempt to design the event to facilitate social interactions and provide satisfactory leisure experiences. It has been well-documented that people attend special events to socialize with their family and friends and/or meet new people (Taylor and Shanka 2008), and such social interactions foster camaraderie — a sense of belonging and solidarity among attendees (Filo, Funk, and O'Brien 2014). Given the identified interaction between camaraderie and noncause motivation, it is important to provide social places (for example, social media sites, onsite venues) primarily catering to leisure-focused participants and allow them to share their interest in the focal leisure activity with others. At the same time, charitable organizations should spread cause-related information at those places to increase the awareness of and support for the cause among leisure-focused participants.

Regarding event satisfaction, it is important to note that participants of the current event and other special events examined in past studies (Hendriks and Peelen 2013; Wharf Higgins and Hodgings 2008) generally reported a high level of satisfaction with their event participation. This implies a ceiling effect, in which increasing event satisfaction further would not strongly affect donation intention. On the other hand, as indicated by the upper graph of Figure 2, a reduction in event satisfaction can substantially decrease the donation intention of attendees especially with a 
noncause motivation. The preceding discussion collectively informs charitable organizations of the need to maintain (more than improve) the current level of event satisfaction. In this regard, the event literature has demonstrated that factors that can increase event satisfaction are distinguishable from factors that can cause event dissatisfaction, with the latter entailing event maintenance attributes, such as the convenience of parking, cleanness and availability of rest rooms, and availability of information services (Crompton 2003). Thus, charitable organizations are encouraged to carefully assess that such maintenance attributes meet attendees' expectation so as not to reduce their level of event satisfaction.

The findings can provide further insight into the postevent activities of charitable organizations. Specifically, although postevent efforts (for example, sending solicitation letters) are essential to develop event attendees into active donors (Webber 2004), the effectiveness of such efforts can be greatly influenced by the types of messages a charitable organization delivers (James 2015). In this regard, the findings indicate that a charitable organization may be able to increase the likelihood of giving among event attendees by developing its postevent messages based on the three event-related attributes found to affect donation intention. Examples include a message detailing how much the special event has contributed to the cause through donations and increased awareness (for perceived event contribution), event highlights and recap including race/tournament results (for event satisfaction), and fellow attendees' personal stories about their social interactions at the event (for camaraderie).

\section{Limitations and Conclusions}

Some limitations of this study should be noted. First, the generalizability of the current results to the population is limited because of convenience sampling and nonresponse bias. Although the final sample size was fairly large $(N=696)$, all study participants were 
conveniently selected based on the availability of email addresses. The analysis for nonresponse bias also suggested a potential overrepresentation of younger attendees in the final sample.

Consequently, this study's inability to generalize the results to all attendees of the special event investigated constitutes a limitation.

Second, the findings have limited external validity because the study was conducted at one particular special event, namely, a professional golf tournament supporting a local nonprofit hospital. The three event-related attributes examined in this study can still be assumed to play a significant role in predicting attendees' donation intention for different types of special events because the importance of these attributes has been consistently acknowledged by previous studies examining other special events (Filo, Funk, and O’Brien 2014; Webber 2004; Wharf Higgins and Lauzon 2003). In addition, professional golf tournaments are increasingly used for fundraising efforts (see Inoue and Havard, 2014, for further discussion on the use of such tournaments for special events), thereby constituting an appropriate research setting to address the research question of this study. Nevertheless, this type of special event likely attracts a specific group of individuals (well-educated, affluent, older, white male for the current event) that are different from participants of special events using other leisure activities, such as music concerts and physical activity. Hence, this study's findings must be confirmed through examinations of other types of special events. Furthermore, in the current setting, strong cause support was apparent with over $70 \%$ of the respondents indicating that their primary motivation for attending the event was to support the cause. It is desirable to assess the main effects of the three event-related attributes and interaction effects of the event attendance motivation at events that attract more leisure-focused participants. 
Third, despite the practical significance of the current results, the vast majority of the variance in donation intention remained unexplained in the final model. Building on this study, future researchers should examine additional event-related attributes as well as personal characteristics that might affect event attendees' donation intention beyond their event attendance. For example, evidence from the charitable giving literature (Bekkers and Wiepking 2011) suggests that attendees' personal values would likely affect their donation intention. Attendees' support for a cause can also be influenced by their relationships with the cause, such as whether they or their significant others are personally affected by the cause (for example, cancer survivors) and the extent to which they identify with the charitable organization (Cornwell and Coote 2005). Moreover, while this study focused on attributes that can influence attendees' perceived benefits from a special event, research on charitable giving has demonstrated that the costs associated with giving also affect the decision to donate money to a charitable organization (Bekkers and Wiepking 2011). Therefore, attendees' donation intention might be determined by their perception of the costs of participating in a special event, such as the amount of participation fees.

Fourth, the theoretical propositions of this study were explicitly drawn from the literature and were tested using a survey design. To obtain participants' perspectives on these propositions as well as additional factors that could affect their future donations, future studies are encouraged to employ an in-depth qualitative design. Finally, the examination of donation intention limits this study's ability to infer the extent to which the three attributes influenced the donation behavior of the event attendees. Therefore, linking these attributes to actual donation data would be a logical next step in this line of inquiry. 


\section{Author Information}

Yuhei Inoue, $\mathrm{PhD}$, is an Assistant Professor of Sport Management in the School of Kinesiology at the University of Minnesota, USA. His primary research interest is to understand the ability of sport organizations and athletes to promote positive social development. The author would like to thank Cody Havard and Mikihiro Sato for their valuable feedback on the earlier versions of this article. 


\section{References}

Ariely, D., A. Bracha, and S. Meier. 2009. "Doing Good or Doing Well? Image Motivation and Monetary Incentives in Behaving Prosocially." The American Economic Review 99 (1): 544-55.

Bagozzi, R. P. 1975. “Marketing as Exchange.” Journal of Marketing 39 (4): 32-39.

Bekkers, R., and P. Wiepking. 2011. "A Literature Review of Empirical Studies of Philanthropy: Eight Mechanisms That Drive Charitable Giving." Nonprofit and Voluntary Sector Quarterly 40 (5): 924-73.

Brambor, T., W. R. Clark, and M. Golder. 2006. "Understanding Interaction Models: Improving Empirical Analyses." Political Analysis 14 (1): 63-82.

Brown, E., and J. M. Ferris. 2007. "Social Capital and Philanthropy: An Analysis of the Impact of Social Capital on Individual Giving and Volunteering." Nonprofit and Voluntary Sector Quarterly 36 (1): 85-99.

Chalip, L. 2006. "Towards Social Leverage of Sport Events.” Journal of Sport \& Tourism 11 (2): $109-27$.

Cornwell, T. B., and L. V. Coote. 2005. "Corporate Sponsorship of a Cause: The Role of Identification in Purchase Intent." Journal of Business Research 58 (3): 268-76.

Crompton, J. L. 2003. "Adapting Herzberg: A Conceptualization of the Effects of Hygiene and Motivator Attributes on Perceptions of Event Quality." Journal of Travel Research 41 (3): 305-10.

Cropanzano, R., and M. S. Mitchell. 2005. "Social Exchange Theory: An Interdisciplinary Review." Journal of Management 31 (6): 874-900.

Croson, R., F. Handy, and J. Shang. 2009. "Keeping up with the Joneses: The Relationship of Perceived Descriptive Social Norms, Social Information, and Charitable Giving." Nonprofit Management and Leadership 19 (4): 467-89.

Curtis, D., R. A. Cnaan, and V. Evans. 2014. "Motivating Mormons.” Nonprofit Management and Leadership 25 (2): 131-45.

Einolf, C. J., D. M. Philbrick, and K. Slay. 2013. "National Giving Campaigns in the United States: Entertainment, Empathy, and the National Peer Group." Nonprofit and Voluntary Sector Quarterly 42 (2): 241-61.

Ferguson, E., K. Farrell, and C. Lawrence. 2008. "Blood Donation Is an Act of Benevolence rather than Altruism." Health Psychology 27 (3): 327-36.

Filo, K., D. C. Funk, and D. O’Brien. 2009. “The Meaning behind Attachment: Exploring Camaraderie, Cause, and Competency at a Charity Sport Event." Journal of Sport Management 23 (3): 361-87.

Filo, K., D. C. Funk, and D. O’Brien. 2014. “An Empirical Investigation of the Role of Camaraderie, Cause, Competency, and Participation Motives in the Development of Attachment to a Charity Sport Event." Managing Leisure 19 (4): 245-62.

Forbes, K. F., and E. M. Zampelli. 2014. "Volunteerism: The Influences of Social, Religious, and Human Capital." Nonprofit and Voluntary Sector Quarterly 43 (2): 227-53.

Gaier, S. 2005. "Alumni Satisfaction with Their Undergraduate Academic Experience and the Impact on Alumni Giving and Participation." International Journal of Educational Advancement 5 (4): 279-88.

Giese, J. L., and J. A. Cote. 2000. "Defining Consumer Satisfaction.” Academy of Marketing Science Review 1 (1): 1-24. 
Hendriks, M., and E. Peelen. 2013. "Personas in Action: Linking Event Participation Motivation to Charitable Giving and Sports." International Journal of Nonprofit and Voluntary Sector Marketing 18 (1): 60-72.

Inoue, Y., and C. T. Havard. 2014. "Determinants and Consequences of the Perceived Social Impact of a Sport Event." Journal of Sport Management 28 (3): 295-310.

Inoue, Y., C. T. Havard, and R. L. Irwin. forthcoming. "Roles of Sport and Cause Involvement in Determining Employees' Beliefs about Cause-Related Sport Sponsorship." International Journal of Sports Marketing \& Sponsorship.

James, R. N. 2015. "The Family Tribute in Charitable Bequest Giving.” Nonprofit Management and Leadership, Advance online publication. http://dx.doi.org/10.1002/nml.21141

Leslie, L. M., M. Snyder, and T. M. Glomb. 2013. "Who Gives? Multilevel Effects of Gender and Ethnicity on Workplace Charitable Giving." Journal of Applied Psychology 98 (1): 49-62.

Levi-Strauss, C. 1969. The Elementary Structure of Kinship. Boston, MA: Beacon Press.

Lichtenstein, D. R., M. E. Drumwright, and B. M. Braig. 2004. "The Effect of Corporate Social Responsibility on Customer Donations to Corporate-Supported Nonprofits." Journal of Marketing 68 (4): 16-32.

Lindner, J. R., T. H. Murphy, and G. E. Briers. 2001. "Handling Nonresponse in Social Science Research." Journal of Agricultural Education 42 (4): 43-53.

National Association of Basketball Coaches. 2012. "About the Coaches vs Cancer Classic." http://www.cvcclassic.com/about.

Parris, D. L., and J. W. Peachey. 2012. "Building a Legacy of Volunteers through Servant Leadership: A Cause-Related Sporting Event." Nonprofit Management and Leadership 23 (2): 259-76.

Podsakoff, P. M., S. B. MacKenzie, J. Lee, and N. P. Podsakoff. 2003. "Common Method Biases in Behavioral Research: A Critical Review of the Literature and Recommended Remedies." Journal of Applied Psychology 88 (5): 879-903.

Prince, R. A., and K. File. 1994. The Seven Faces of Philanthropy: A New Approach to Cultivating Major Donors. San Francisco, CA: Jossey-Bass.

Putnam, R. D. 1995. "Bowling Alone: America's Declining Social Capital." Journal of Democracy 6 (1): 65-78.

Sargeant, A. 2001. "Relationship Fundraising: How to Keep Donors Loyal." Nonprofit Management and Leadership 12 (2): 177-92.

Sargeant, A., and J. Hudson. 2008. "Donor Retention: An Exploratory Study of Door-to-Door Recruits." International Journal of Nonprofit and Voluntary Sector Marketing 13 (1): 89101.

Sargeant, A., and L. Woodliffe. 2007. "Building Donor Loyalty: The Antecedents and Role of Commitment in the Context of Charity Giving." Journal of Nonprofit \& Public Sector Marketing 18 (2): 47-68.

Sokolowski, S. W. 1996. "Show Me the Way to the next Worthy Deed: Towards a Microstructural Theory of Volunteering and Giving." Voluntas: International Journal of Voluntary and Nonprofit Organizations 7 (3): 259-78.

Tabachnick, B. G., and L. S. Fidell. 2006. Using Multivariate Statistics. 5th ed. Needham Heights, MA: Allyn \& Bacon.

Taylor, R., and T. Shanka. 2008. "Cause for Event: Not-for-Profit Marketing through Participant Sports Events." Journal of Marketing Management 24 (9-10): 945-58. 
Wang, L., and R. F. Ashcraft. 2014. "Organizational Commitment and Involvement: Explaining the Decision to Give to Associations." Nonprofit and Voluntary Sector Quarterly 43 (April): $61 \mathrm{~S}-83 \mathrm{~S}$.

Wang, L., and E. Graddy. 2008. "Social Capital, Volunteering, and Charitable Giving." VOLUNTAS: International Journal of Voluntary and Nonprofit Organizations 19 (1): 23-42.

Webber, D. 2004. "Understanding Charity Fundraising Events.” International Journal of Nonprofit and Voluntary Sector Marketing 9 (2): 122-34.

Wharf Higgins, J., and A. Hodgings. 2008. "The Grape Escape-A FUNdraising Bike Tour for the Multiple Sclerosis Society." Journal of Nonprofit \& Public Sector Marketing 19 (2): 49-67.

Wharf Higgins, J., and L. Lauzon. 2003. "Finding the Funds in Fun Runs: Exploring Physical Activity Events as Fundraising Tools in the Nonprofit Sector." International Journal of Nonprofit and Voluntary Sector Marketing 8 (4): 363-77.

Woolf, J., B. Heere, and M. Walker. 2013. 'Do Charity Sport Events Function as 'Brandfests' in the Development of Brand Community?.” Journal of Sport Management 27 (2): 95-107.

Yoon, Y., J. Lee, and C. Lee. 2010. 'Measuring Festival Quality and Value Affecting Visitors' Satisfaction and Loyalty Using a Structural Approach.” International Journal of Hospitality Management 29 (2): 335-42. 
Table 1. Characteristics of the Study Participants

\begin{tabular}{|c|c|c|}
\hline Characteristic & $f$ & $\%$ \\
\hline \multicolumn{3}{|l|}{ Gender } \\
\hline Male & 511 & 73.4 \\
\hline Female & 185 & 26.6 \\
\hline \multicolumn{3}{|l|}{ Race / Ethnicity } \\
\hline White & 638 & 91.7 \\
\hline Other & 58 & 8.3 \\
\hline \multicolumn{3}{|l|}{ Age } \\
\hline $18-19$ & 4 & .6 \\
\hline $20-24$ & 11 & 1.6 \\
\hline $25-34$ & 82 & 11.8 \\
\hline $35-44$ & 96 & 13.8 \\
\hline $45-54$ & 153 & 22.0 \\
\hline $55-64$ & 219 & 31.5 \\
\hline $65+$ & 131 & 18.8 \\
\hline \multicolumn{3}{|l|}{ Highest education } \\
\hline Less than high school & 1 & .1 \\
\hline High school / GED & 36 & 5.2 \\
\hline Some college & 126 & 18.1 \\
\hline 2-year college degree & 51 & 7.3 \\
\hline 4-year college degree & 292 & 42.0 \\
\hline Graduate degree & 190 & 27.3 \\
\hline \multicolumn{3}{|l|}{ Household income } \\
\hline Not disclosed & 95 & 13.6 \\
\hline$<\$ 25,000$ & 6 & .9 \\
\hline$\$ 25,001-\$ 50,000$ & 55 & 7.9 \\
\hline$\$ 50,001-\$ 100,000$ & 213 & 30.6 \\
\hline$\$ 100,001-\$ 150,000$ & 155 & 22.3 \\
\hline$\$ 150,001-\$ 200,000$ & 75 & 10.8 \\
\hline$\$ 200,001+$ & 97 & 13.9 \\
\hline \multicolumn{3}{|l|}{ Resident status } \\
\hline Local & 442 & 63.5 \\
\hline Visitor & 254 & 36.5 \\
\hline \multicolumn{3}{|c|}{ Primary attendance motivation } \\
\hline To support the cause & 514 & 73.9 \\
\hline Other & 182 & 26.1 \\
\hline Total & 696 & 100.0 \\
\hline
\end{tabular}


Table 2. Descriptive Statistics and Correlations for the Independent and Dependent

\begin{tabular}{lcccccc}
\multicolumn{1}{c}{ Variable } & $M$ & $S D$ & 1 & 2 & 3 & 4 \\
& & & & & & \\
\hline 1. Event satisfaction & 0.90 & 0.19 & $(.79)$ & & \\
2. Perceived event contribution & 0.83 & 0.24 & $.43^{* *}$ & $(.85)$ & \\
3. Camaraderie & 0.52 & 0.28 & $.38^{* *}$ & $.37^{* *}$ & $(.84)$ \\
4. Donation intention & 0.68 & 0.33 & $.29^{* *}$ & $.35^{* *}$ & $.30^{* *}$ & -
\end{tabular}

Note. $N=696$. The diagonal matrix shows Cronbach's alphas in parentheses. For all variables, transformed values based on the reflect and inverse function were used.

${ }^{* *} p<.01$. 
Table 3. Unstandardized Results of Multiple Regression Analyses Predicting Donation Intention

\begin{tabular}{|c|c|c|c|c|c|c|c|c|}
\hline \multirow[b]{2}{*}{ Variable } & \multicolumn{2}{|c|}{ Model 1} & \multicolumn{2}{|c|}{ Model 2} & \multicolumn{2}{|c|}{ Model 3} & \multicolumn{2}{|c|}{ Model 4} \\
\hline & $B$ & $t$ & $B$ & $t$ & $B$ & $t$ & $B$ & $t$ \\
\hline Gender & $-0.08^{* *}$ & -2.93 & $-0.07^{*}$ & -2.54 & $-0.07^{*}$ & -2.49 & $-0.06^{*}$ & -2.29 \\
\hline Race & $-0.10^{*}$ & -2.29 & -0.08 & -1.83 & $-0.09^{*}$ & -2.04 & -0.08 & -1.96 \\
\hline Age & -0.00 & -0.11 & -0.01 & -0.61 & -0.01 & -0.67 & -0.01 & -0.66 \\
\hline Education & -0.02 & -1.94 & -0.02 & -1.58 & -0.02 & -1.60 & -0.02 & -1.61 \\
\hline Income: Not disclosed & $-0.12^{* *}$ & -2.63 & -0.08 & -1.86 & -0.08 & -1.84 & -0.08 & -1.85 \\
\hline Income: $<\$ 25,000$ & -0.12 & -0.92 & 0.02 & 0.17 & 0.01 & 0.09 & 0.01 & 0.07 \\
\hline Income: $\$ 25,001-\$ 50,000$ & $-0.16^{* *}$ & -2.98 & $-0.14^{* *}$ & -2.64 & $-0.14^{* *}$ & -2.67 & $-0.14^{* *}$ & -2.69 \\
\hline Income: $\$ 50,001-\$ 100,000$ & $-0.09^{*}$ & -2.17 & $-0.09^{*}$ & -2.30 & $-0.09^{*}$ & -2.29 & $-0.09^{*}$ & -2.32 \\
\hline Income: $\$ 100,001-\$ 150,000$ & -0.07 & -1.77 & -0.07 & -1.68 & -0.07 & -1.72 & -0.07 & -1.79 \\
\hline Income: $\$ 150,001-\$ 200,000$ & -0.02 & -0.32 & -0.01 & -0.26 & -0.01 & -0.16 & -0.01 & -0.15 \\
\hline Resident status & -0.01 & -0.32 & -0.01 & -0.59 & -0.01 & -0.60 & -0.01 & -0.60 \\
\hline Event participation & $0.03^{* *}$ & 4.48 & $0.01^{*}$ & 2.28 & $0.01^{*}$ & 2.24 & $0.01^{*}$ & 2.34 \\
\hline Noncause motivation & $-0.16^{* *}$ & -5.63 & $-0.12^{* *}$ & -4.38 & $-0.34^{* *}$ & -3.01 & $-0.25^{* *}$ & -4.77 \\
\hline Event satisfaction & & & $0.20^{* *}$ & 2.91 & 0.10 & 1.26 & $0.19^{* *}$ & 2.85 \\
\hline Perceived event contribution & & & $0.29^{* *}$ & 5.35 & $0.30^{* *}$ & 5.47 & $0.29^{* *}$ & 5.24 \\
\hline Camaraderie & & & $0.13^{* *}$ & 2.87 & $0.14^{* *}$ & 2.97 & 0.07 & 1.41 \\
\hline Noncause motivation $\times$ Event satisfaction & & & & & $0.25^{*}$ & 2.01 & & \\
\hline Noncause motivation $\times$ Camaraderie & & & & & & & $0.28^{* *}$ & 2.90 \\
\hline$R^{2}$ & .12 & & .22 & & .23 & & .23 & \\
\hline$\Delta R^{2}$ & & & $.10^{* *}$ & & $.01^{* *}, \mathrm{a}$ & & $.01^{* *}, \mathrm{a}$ & \\
\hline
\end{tabular}

Note. $N=696$.

a Difference from Model 2 is calculated.

${ }^{*} p<.05$. ${ }^{* *} p<.01$. 
Figure 1. Research Model

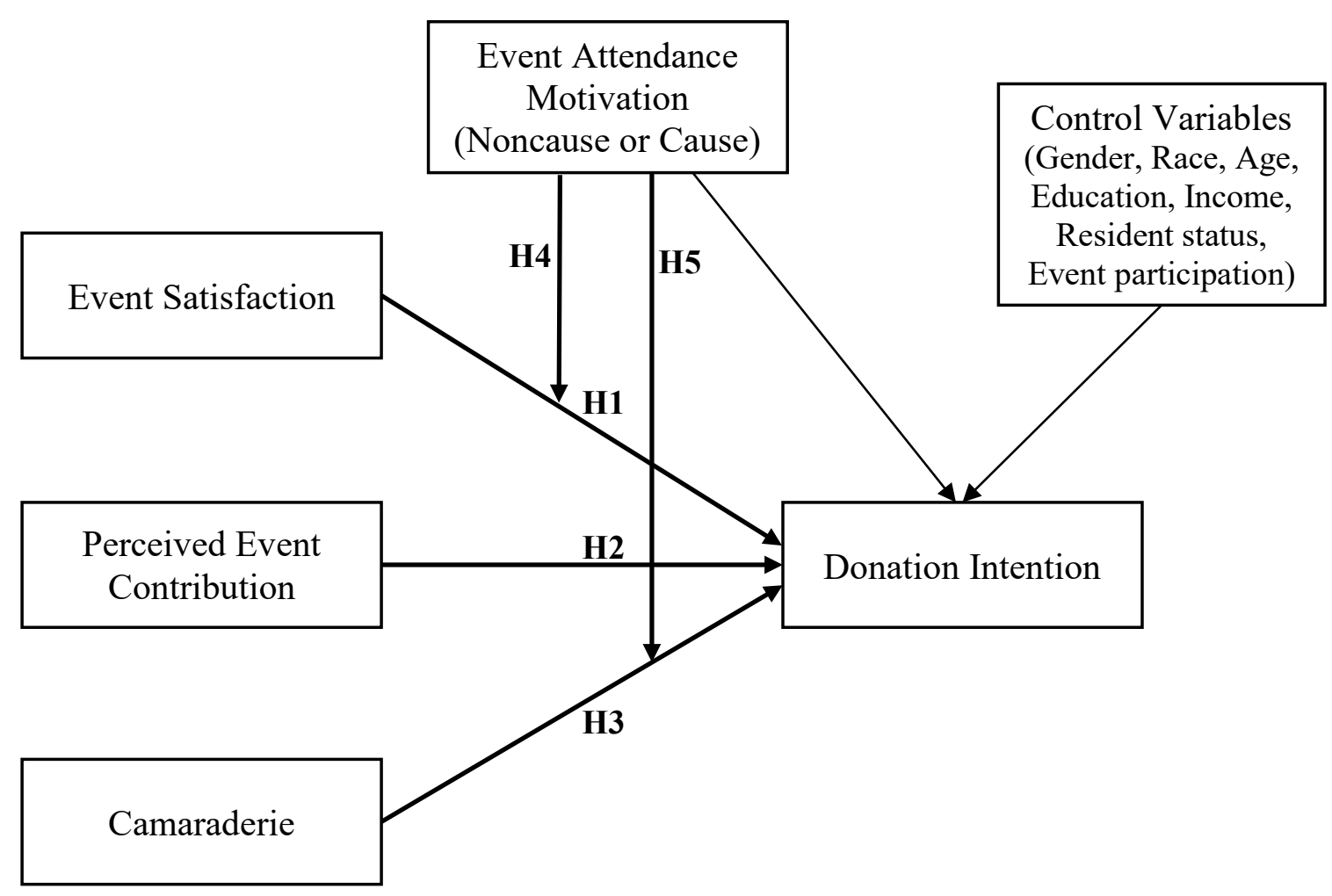

Note. $\mathrm{H}=$ Hypothesis. The bold lines represent the hypothesized paths. 
Figure 2. Interaction Effect of Event Attendance Motivation

a. Interaction between Noncause Motivation and Event Satisfaction

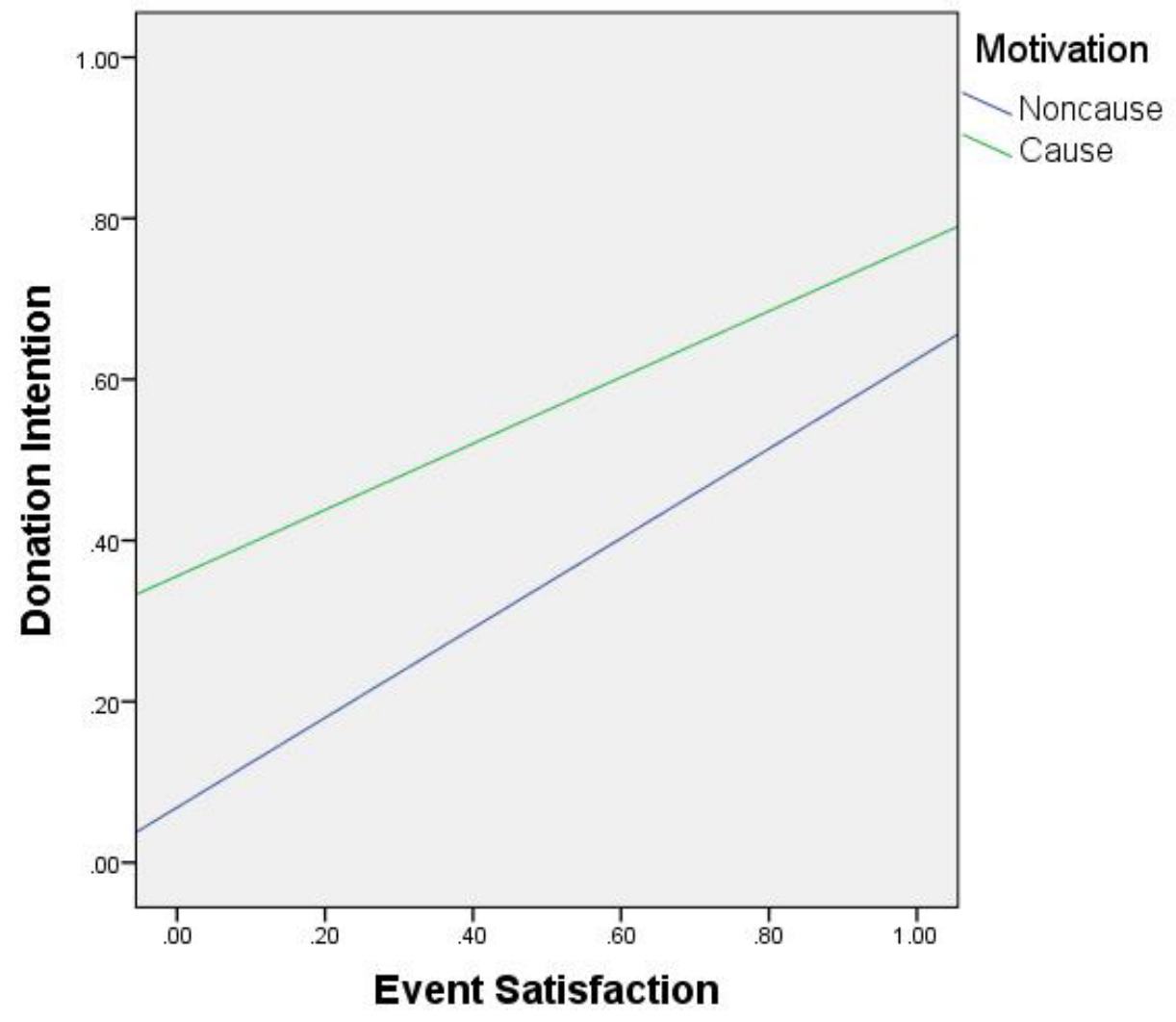

b. Interaction between Noncause Motivation and Camaraderie

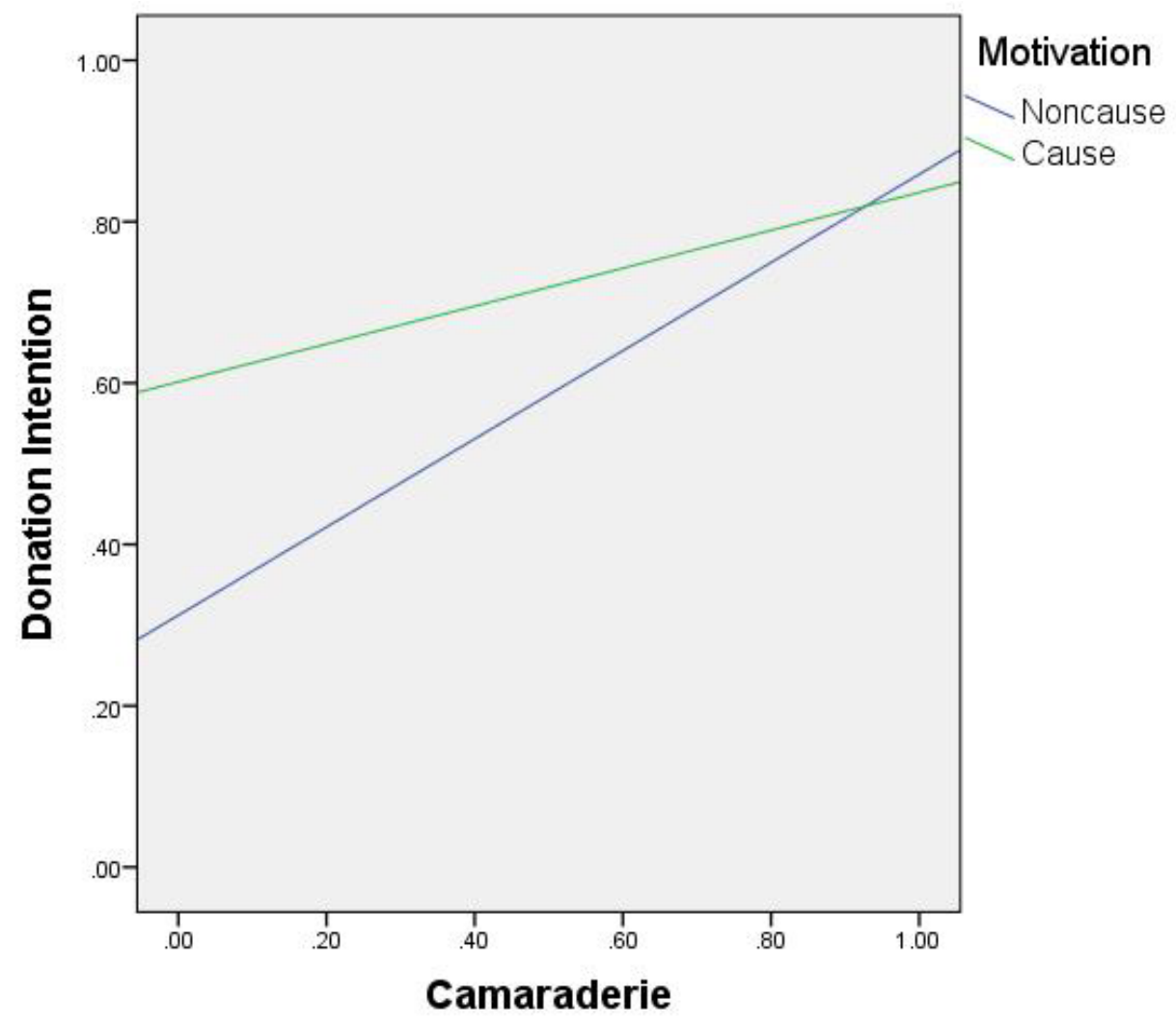

